\title{
Chemical modification of $\beta$-cyclodextrins: Balancing soft and rigid domains in complex structures
}

\author{
Federico Luppi, ${ }^{[a]}$ Nathalie Mai, ${ }^{[a]}$ Guillaume Kister, ${ }^{[a]}$ Philip P. Gill, ${ }^{[a]}$ Sally E. Gaulter, ${ }^{[a]}$ Christopher \\ Stennett, ${ }^{[a]}$ and Eleftheria Dossi ${ }^{*[a]}$
}

\begin{abstract}
Crystalline polymers such as $\beta$-cyclodextrin $(\beta C D)$ can be modified with polyethylene glycol (PEG) diglycidyl ether cross-linkers $(262,394,500 \mathrm{Da})$. Here we show that the quantity and length of the PEG soft segments influence the solubility and malleability of the products, which are water-soluble and easily converted to nitrated analogues under standard reaction conditions. Inert and nitrated derivatives containing longer PEG segments showed the ability to self-heal. The degree of cross-linking and decomposition temperatures and energies depended on the quantity and length of the soft segment. Nitrated cross-linked $\beta C D$ containing longer PEG segments did not ignite following an electrostatic discharge of $4.5 \mathrm{~J}$. The chemical stability of $\beta C D / P E G$ binders was tested by heat flow calorimetry at $80^{\circ} \mathrm{C}$. We found that the balanced incorporation of soft $P E G$ and rigid $\beta C D$ segments improved the processability of crosslinked $\beta C D$ s and desensitised their nitrated derivatives, offering new solutions for inert and energetic binders.
\end{abstract}

\section{Introduction}

Energetic formulations used in the defence industry must withstand unintended stimuli (such as shock and heat) to avoid premature ignition. Manufacturing is therefore moving towards improved safety during production and storage. Indeed, the development of insensitive munitions is a direct response to several accidents that caused the involuntary initiation of explosives. ${ }^{[1]} \mathrm{A}$ systems approach has been adopted, and many design concepts may be combined, including munition design, packaging design and the selection of energetic materials. ${ }^{[1]}$ Energetic materials with low vulnerability can prevent unwanted initiation events.

Polymers were introduced into energetic formulations as a medium to bind the explosive ingredients, thus increasing the density of the munitions and reducing their vulnerability. ${ }^{[2]}$ Polymeric binders strongly influence the performance of propellants and explosives, which depends on the shape, surface area, and mechanical integrity of the formulation. ${ }^{[3,4]}$ The viscoelastic behaviour of the binder facilitates energy dissipation by reducing susceptibility to damage and particle de-wetting caused by mechanical stress. ${ }^{[5]}$

[a] Dr Federico Luppi, Dr Nathalie Mai, Dr Guillaume Kister, Dr Philip P. Gill, Miss Sally E. Gaulter, Dr Christopher Stennett, Dr Eleftheria Dossi

Centre for Defence Chemistry, Cranfield University

Defence Academy of United Kingdom, Shrivenham, SN6 8LA, UK E-mail: e.dossi@cranfield.ac.uk (E.Dossi)

Supporting information for this article is given via a link at the end of the document
Nitrocellulose (NC), prepared by the nitration of cellulose, was the first polymer used as a binder in smokeless propellants. ${ }^{[2]}$ Several classes of polymers have been used as binders, including polysulfides, polybutadienes, polyurethanes, polyacrylates and fluoropolymers. ${ }^{[2]}$ Hydroxyl-terminated polybutadiene (HTPB) is the most widely-used polymeric binder because of its low viscosity, which improves the loading of solids and produces consistent mechanical properties. ${ }^{[2]}$ HTPB also benefits from wellestablished isocyanate cure chemistry, although non-toxic curing agents are a recent innovation. ${ }^{[6]}$ However, HTPB is nonenergetic, limiting the performance of the composition. Energetic binders can be prepared by introducing certain energetic groups such as azide $\left(-\mathrm{N}_{3}\right)$, nitro $\left(-\mathrm{NO}_{2}\right)$ or nitrato $\left(-\mathrm{ONO}_{2}\right)$, contributing to the total energy of the composition and enhancing its performance. ${ }^{[2]}$ Various energetic polymers and their copolymers have been developed in this manner, including glycidyl azide polymer (GAP), polyglycidyl nitrate (PGN), polyoxetanes such as poly(BAMMO), poly(AMMO), poly(NIMMO) and poly(GLYN), ${ }^{[7]}$ and substituted polyphosphazenes with azido and nitrate pendant groups ${ }^{[8]}$ The nitration of HTPB has also produced recent promising results. ${ }^{[9]}$ Nitrated cyclodextrins (CDs) have been used in an attempt to replace NC with natural CDs as building blocks for energetic binders. [10] The intent is to overcome the inconsistent physicochemical properties of cellulose, the NC precursor. The selection and certification process for cotton batches intended for NC production is long and expensive. ${ }^{[7,11,12]}$

The three best-known CDs are $\alpha$-cyclodextrin $(\alpha C D)$, $\beta$-cyclodextrin ( $\beta C D)$, and $\gamma$-cyclodextrin $(\gamma C D)$, which are toroidal macrocycles of six, seven and eight glucopyranose units, respectively. ${ }^{[13]} \mathrm{CDs}$ have been chemically modified to adjust their solubility, bioavailability and inclusion complex stability. ${ }^{[13,14]}$ There is great interest in these compounds, reflecting their ability to form supramolecular structures with exploitable guest-host interactions. ${ }^{[15-19]}$ CDs containing polyethylene glycol (PEG) soft units have been widely used to synthesise drug carrier gels for pharmaceutical applications. ${ }^{[20-27]}$ Drug carriers must maintain their integrity to deliver the drug to a specific target. In addition, several hydrogels based on CD/PEG compounds have shown an ability to self-heal, which means they can fully or partially regenerate their original mechanical properties after damage. ${ }^{[23,28,29]}$

Nitrated $\beta C D$ s ( $\beta N C D s)$ cross-linked with epichlorohydrin and isocyanates have been used to develop patented energetic formulations that are less vulnerable to accidental stimuli. ${ }^{[11,12]}$ The hazard properties of the energetic materials must be assessed, and tests have been developed to determine the strength of the response to thermal, mechanical and electrical stimuli, and the shelf-life of such substances. ${ }^{[30-32]}$ The $\beta N C D s$ were found to be sensitive to an electrostatic discharge (ESD) of 
$0.0125 \mathrm{~J}$. Although the formulations remained vulnerable to ESD, the energy input required for ignition of the binders is low $(0.1288$ $\mathrm{J})$, which is higher than the value for explosives such as RDX $(0.0585 \mathrm{~J})$ and the $0.02 \mathrm{~J}$ that can potentially be accumulated by an operator. ${ }^{[32]}$ This can be attributed to the accumulation of electrostatic interactions between crystalline regions of the binder. ${ }^{[33]}$

To overcome the sensitivity of $\beta N C D s,{ }^{[11]}$ we recently developed new water-soluble cross-linked $\beta C D$ structures containing soft PEG segments, and their nitrated counterparts. ${ }^{[10,34]}$ The crosslinked $\beta C D / P E G$ derivatives were prepared in order to improve resistance to accidental stimuli and facilitate processing as lacquers, as seen in formulations based on NC. ${ }^{[35]}$ Here we describe the development of two new sets of cross-linked $\beta C D$ s (and their nitrated derivatives) using a family of diglycidyl ethers with variable PEG soft chains, and their comparison to the earlier $\beta C D / P E G$ structures. ${ }^{[10,34]}$ We investigated the effect of the length and quantity of PEG chains on the hazard properties of the binders, revealing their potential for energetic formulations.

\section{Results and Discussion}

The synthesis of cross-linked $\beta C D$ s using PEG diglycidyl ether (PEGDGE, $500 \mathrm{Da}$ ) was recently reported, ${ }^{[10]}$ yielding inert crosslinked $\beta C D$ s with long PEG spacers, hereafter described as inert PEG-linked $\beta C D$ (abbreviation: IP). In this report, we describe two additional series of water soluble cross-linked $\beta C D$ s prepared under the same conditions but using triethylene glycol diglycidyl ether (TEGDGE, $262 \mathrm{Da}$ ) or hexaethylene glycol diglycidyl ether (HEGDGE, $394 \mathrm{Da}$ ) as cross-linkers ${ }^{[27]}$, yielding inert TEG-linked $\beta C D$ (abbreviation: IT) and inert HEG-linked $\beta C D$ (abbreviation: $\mathrm{IH})$, respectively (Supplementary Information, $\mathrm{SI}$ ).

The water content of the $\beta C D$ precursor was determined by thermal gravimetric analysis (TGA) before each cross-linking reaction. $\mathrm{NaOH}$ (5.6\% aqueous solution) was used to obtain the $\beta C D$ alkoxide solution $\left(0.21 \mathrm{~g}_{\beta C D} \mathrm{~mL}^{-1} \text { aq.NaOH }\right)^{[10]}$ and various molar amounts of TEGDGE, HEGDGE or PEGDGE per $\beta$ CD $(2: 1,3: 1$, $4: 1$ and $5: 1$ ) were added at $30{ }^{\circ} \mathrm{C}$ to convert the alkoxides to the corresponding IT, IH and IP derivatives with yields of up to $70 \%$. The physical appearance of the off-white cross-linked products was dependent on the cross-linker: $\beta C D$ ratio: IH and IP samples were soft and malleable when the ratio was $4: 1$ or $5: 1$, but powdery and brittle when the ratio was $2: 1$ or $3: 1$. Due to the short length of the cross-linker, all IT samples were crystalline and brittle regardless of the TEG: $\beta C D$ ratio. The corresponding nitrated products, were synthesised by mixing the inert precursors (IT, IH or IP) with $100 \%$ nitric acid, resulting in high yields (95\%) of nitrated TEG-linked $\beta C D$ (abbreviation: NT), nitrated HEGlinked $\beta C D$ (abbreviation: $\mathrm{NH}$ ), and nitrated PEG-linked $\beta C D$ (abbreviation: NP), respectively. All NP samples were soluble in acetone. ${ }^{[10]}$

All of the inert and nitrated cross-linked products were characterised by proton nuclear magnetic resonance ( $\left.{ }^{1} \mathrm{H}-\mathrm{NMR}\right)$ in deuterated dimethyl sulfoxide (DMSO- $\mathrm{d}_{6}$ ) to determine the purity and chemical structure (Figure 1), and in deuterium oxide $\left(D_{2} O\right)$ to confirm the cross-linking ratios. ${ }^{[25,10]}$
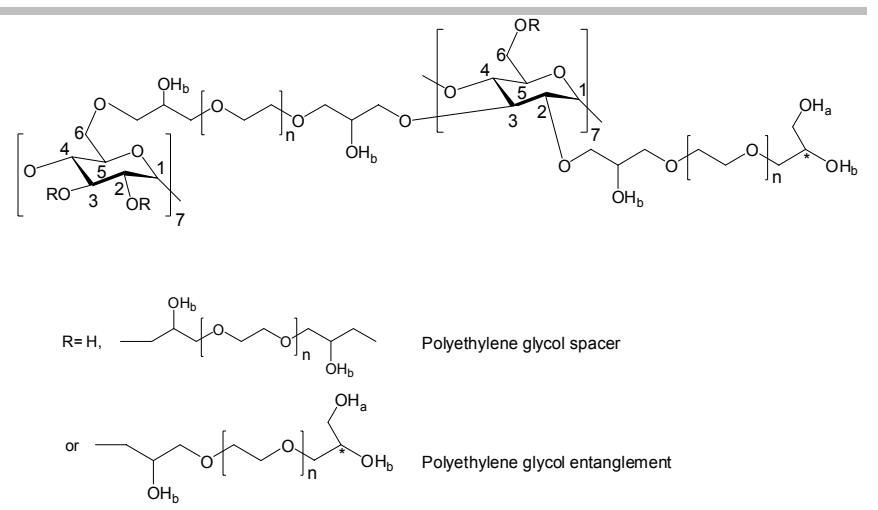

Figure 1 Proposed chemical structure of IT, IH and IP samples. ${ }^{[25,10]}$

The ${ }^{1} \mathrm{H}-\mathrm{NMR}$ spectra of the IT, IH and IP samples, were similar, but the intensity of the signals at $5.15 \mathrm{ppm}$ (Figure 2) assigned to the absorption of the anomeric $\mathrm{H}-1$ protons adjacent to a substituted proton in the $\mathrm{OH}-2$ group (Figure 1, where $\mathrm{R}=\beta C D$, spacer, or entanglement) was proportional to the degree of crosslinking in the samples. Structured absorption peaks were also observed between 3.6 and 3.4 ppm, attributed to the $\mathrm{H}-3$ proton of $\beta C D$ units in samples with less cross-linking (Figure 2 ).

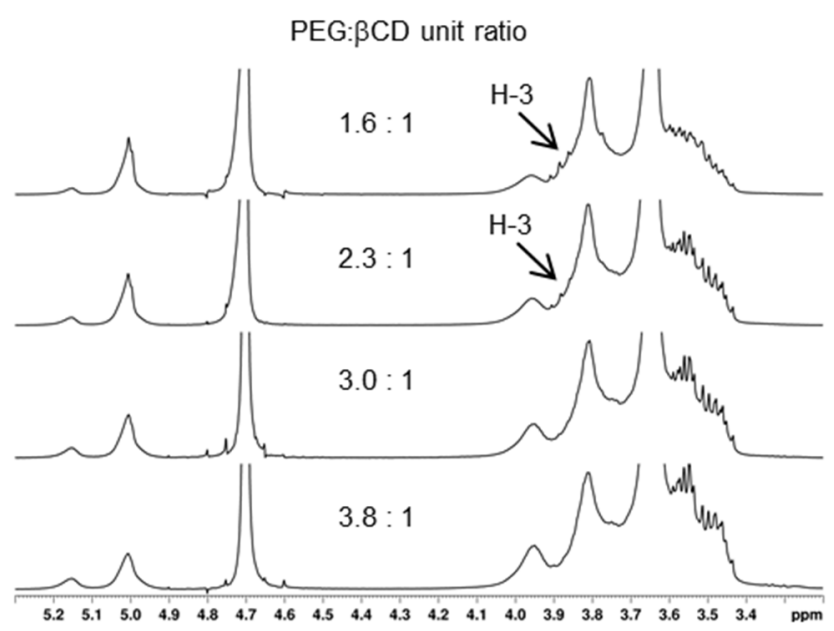

Figure 2 Comparison of ${ }^{1} \mathrm{H}-\mathrm{NMR}$ spectra for IP samples with different $P E G: \beta C D$ unit ratios as indicated. Lower amounts enhance the visibility of the $\beta C D$ proton (arrow).

The estimated cross-linking ratios of the IP, IH and IP samples were $25 \%$ lower than the theoretical maximum ratio that can be achieved based on the linker: $\beta C D$ feed ratio. For example, when a 5:1 PEGDGE: $\beta C D$ feed ratio was used, the PEG: $\beta C D$ unit ratio in the product was 3.8 (Figure 3). This reflected the degradation of the cross-linker under alkaline hydrolysis conditions. ${ }^{[10]}$

The ${ }^{1} \mathrm{H}-\mathrm{NMR}$ spectra of the NP samples were reported in our earlier study. ${ }^{[10]}$ Here, we compared the spectra of the NT, NH and NP samples with the spectrum for $\beta N C D$. No significant differences were observed among the spectra for the nitrated samples containing TEG, HEG or PEG units, with similar degrees of cross-linking in all cases (SI).

All inert and nitrated cross-linked $\beta C D$ s were characterised by Fourier transform infrared (FTIR) spectroscopy and the spectra were compared to those for $\beta C D$ and the pure cross-linkers. $A$ representative example (NP) is shown in Figure 4. The strong absorption at $2940 \mathrm{~cm}^{-1}$ (symmetric stretching of $\mathrm{CH}_{2}$ and $\mathrm{CH}$ ), 
$2871 \mathrm{~cm}^{-1}$ (asymmetric stretching of $\mathrm{CH}_{2}$ and $\mathrm{CH}$ ), $1453 \mathrm{~cm}^{-1}$ (scissoring of $\mathrm{CH}_{2}$ ) and $1349 \mathrm{~cm}^{-1}$ (bending of $\mathrm{CH}$ ) together with the strong absorption at 1077 and $1023 \mathrm{~cm}^{-1}$ (stretching of C-OC) confirmed the presence of cross-linking in the NP sample.

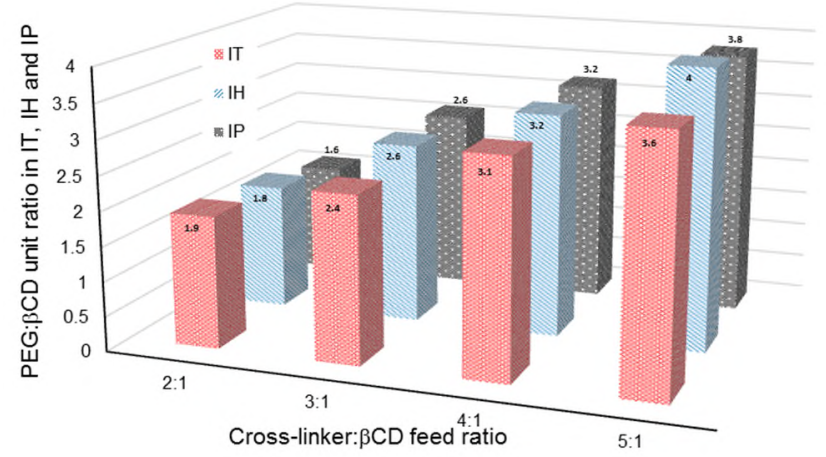

Figure 3 Effect of PEG: $\beta C D$ unit ratio on the degree of cross-linking in IT, IH and IP samples.

The signals in all spectra at $1642 \mathrm{~cm}^{-1}$ represented the secondary vibration of entrapped water molecules in the $\beta C D$ units (up to $15 \%$ by mass). ${ }^{[36]}$

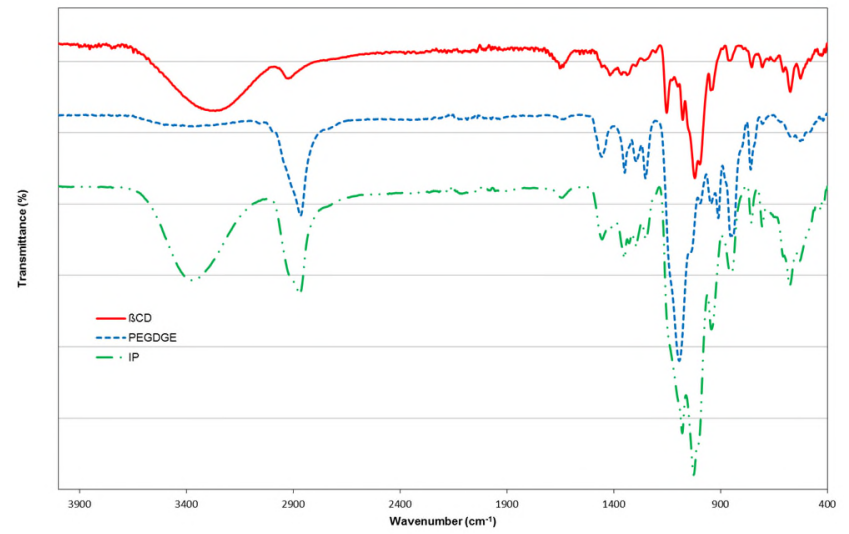

Figure 4 Comparative FTIR spectra of $\beta C D$ (solid line), IP (dashed line), and PEGDGE (dotted line).

The nitrated products were then characterised by FTIR spectroscopy in attenuated total reflectance (ATR) mode for the rapid analysis of solid-phase samples. One representative NP sample is compared with its precursor in Figure 5.

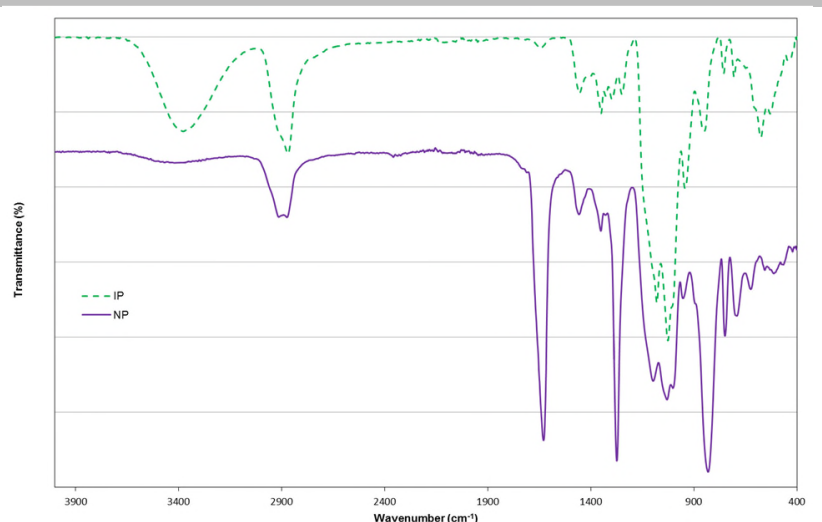

Figure 5 Comparison of FTIR spectra representing NP (solid line) and its inert IP precursor (dashed line).

The broad absorption peak at $3440 \mathrm{~cm}^{-1}$ was assigned to the O$\mathrm{H}$ stretching vibration of the remaining free hydroxyl groups in the cross-linked system, whereas the strong absorptions at 1646 , 1274 and $831 \mathrm{~cm}^{-1}$ confirmed the introduction of nitrato groups.

Next we carried out gel permeation chromatography (GPC) experiments and compared the chromatograms representing $\beta C D$ and its inert and nitrated cross-linked products in aqueous and tetrahydrofuran (THF) solutions, respectively. This confirmed the formation of complex polymeric systems with large hydrodynamic volumes. Polyethylene oxide (PEO)/PEG standards were used for the calibration of the system but the molecular mass distribution of the new compounds was evaluated with respect to the molecular mass distribution of $\beta C D$ (SI). All chromatograms revealed broad Gaussians, where the width was proportional to the quantity and length of the cross-linker. A typical example is shown in Figure 6a. The polydispersity of the crosslinkers is reflected in the shape of the molecular mass distributions of the three different families: IT derivatives of the monodispersed synthetic TEGDGE sample showed a sharper molecular mass distribution than derivatives of $\mathrm{IH}$ and IP $(\mathrm{SI})$. GPC analysis of the nitrated cross-linked products in THF revealed a broad bimodal molecular mass distribution (Figure 6b) dependent on the cross-linker: $\beta C D$ ratio (SI).

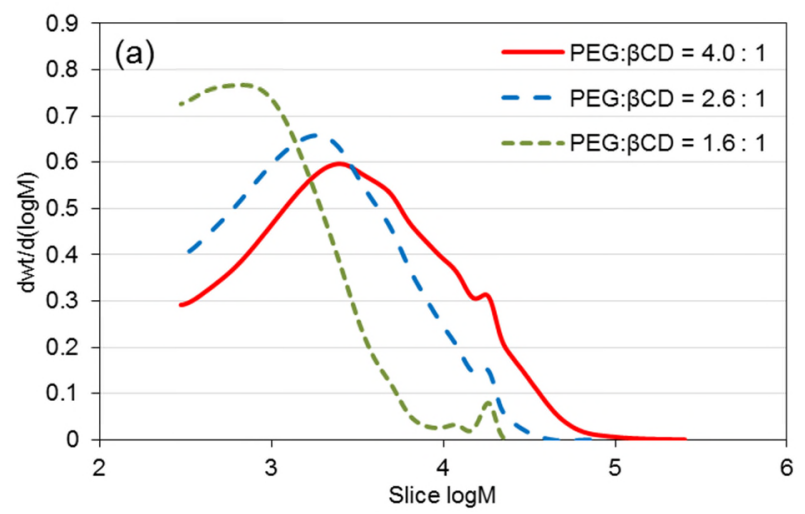




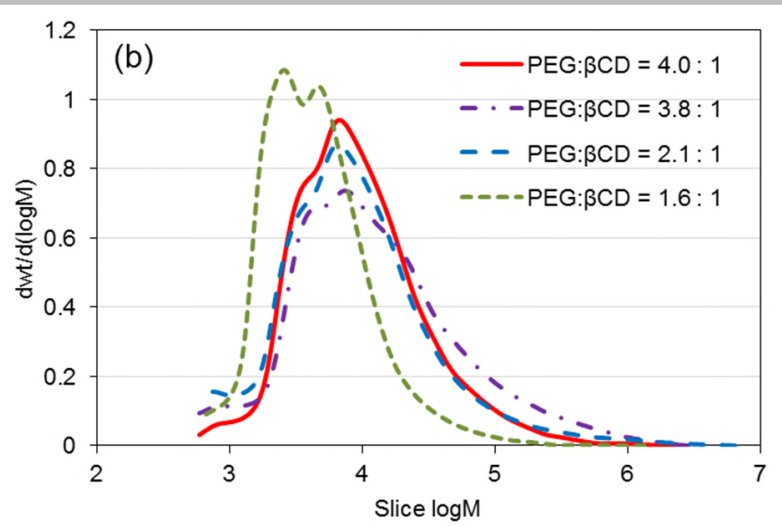

Figure 6 Comparison of molecular mass distribution curves of (a) IP samples and (b) NP samples containing similar PEG: $\beta C D$ unit ratios.

The amorphous surface morphologies of the IT, IH and IP samples were investigated by scanning electron microscopy (SEM) and compared to the microcrystalline form of the $\beta C D$ (Figure 7). The foamy surface appearance of the IT, IH and IP samples reflected the evaporation of residual water during SEM under vacuum (Figures 8 and 9).

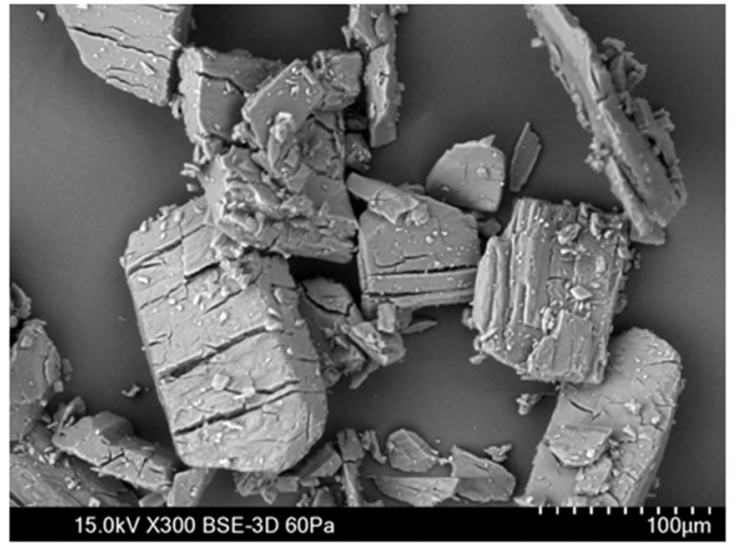

Figure 7 Scanning electron micrograph of $\beta C D$ crystals.

Higher TEG: $\beta C D$ unit ratios (3.6:1 and 3.2:1) in the IT samples resulted in an amorphous surface (Figure 8a,b), whereas lower ratios (2.4:1 and 1.8:1) resulted in more crystalline samples that were similar to $\beta C D$ (Figure $8 \mathrm{c}, \mathrm{d}$ ).

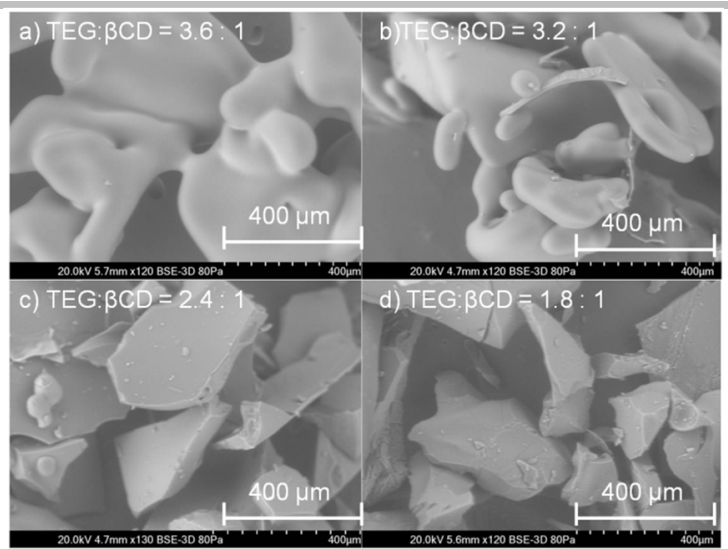

Figure 8 Scanning electron micrographs of IT samples with different TEG: $\beta C D$ unit ratios: (a) 3.6:1 (b) 3.2:1 (c) 2.4:1 and (d) 1.8:1.

However, different ratios of HEG and PEG units relative to $\beta C D$ appeared to have no effect the morphology of the IH and IP samples, which featured homogeneous smooth surfaces (Figure 9). Some crystalline domains were observed in the IP samples with fewer cross-links (Figure 9d) reflecting the higher content of $\beta C D$ units, thus resembling the sparsely cross-linked IT samples (Figure 8d).

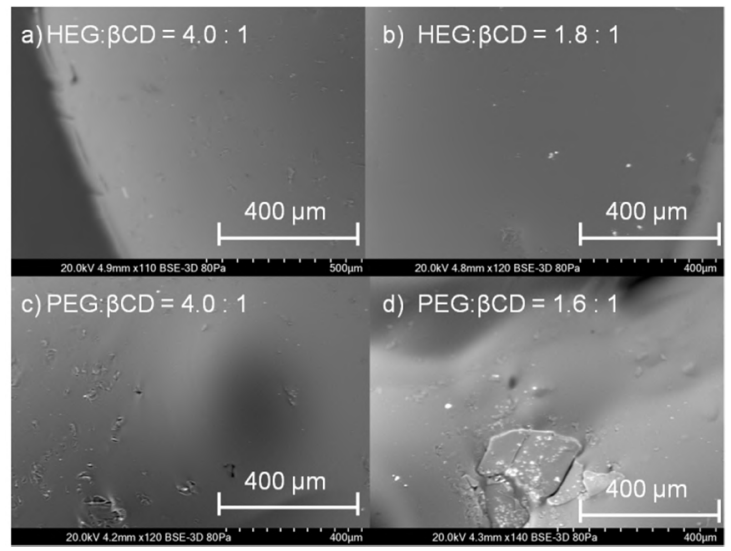

Figure 9 Scanning electron micrographs of $\mathrm{IH}$ samples with different HEG: $\beta C D$ unit ratios of (a) 4.0:1 and (b) 1.8:1, and IP samples with different PEG: $\beta C D$ unit ratios of (c) 4.0:1 and (d) 1.6:1.

The nitrogen content ( $\mathrm{N} \%$ ) of all nitrated cross-linked binders was determined in triplicate by iron sulfate titration. The nitric acid generated from the hydrolysis of the nitrato groups in excess $98 \%$ sulfuric acid forms $\mathrm{NO}_{x}$ complexes with the iron titrant, allowing the determination of the $\mathrm{N} \%$ by colour change using the following equation: ${ }^{[37]}$

$$
N \%=V F / m
$$

where $V$ is the volume of titrant, $F$ is the correction factor, and $m$ is the mass of nitrated sample.

A sample of $\beta C D$ was nitrated under the same conditions to determine the effect of cross-linking on the nitration efficiency 
$(\beta N C D, N \%=11.6)$. As expected, the $\mathrm{N} \%$ of the NT, NH and NP samples declined with increasing quantities of the inert linker units in the molecules. Some deviations from the linear trend of $\mathrm{N} \%$ values (Figure 10) were attributed to the lower efficiency of nitration in the less-soluble inert precursors, which take longer to dissolve in the nitrating medium.

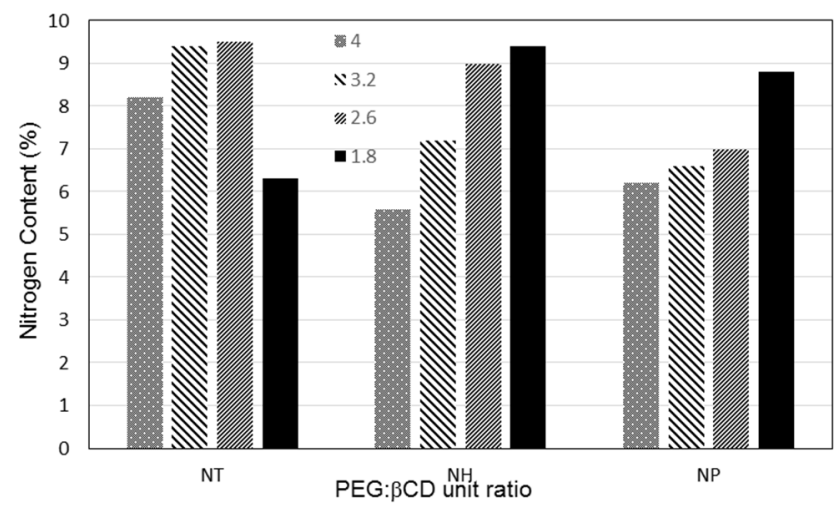

Figure 10 Calculated nitrogen content (N\%) of NT, NH and NP samples. Values are means of three replicate titrations with a variance of $\pm 0.2 \%$.

The degree of nitration (DN) of the NT, NH and NP samples (representing the conversion of hydroxyl protons to nitrato groups) was calculated from the N\% given the assumption (based on ${ }^{1} \mathrm{H}-\mathrm{NMR}$ data) that the chemical composition was not affected by the nitration conditions. All DN values (2.2-3.1) were higher than the $D N$ of the $\beta N C D$ sample (2.1) due to the greater number of hydroxyl groups in the IT, IH and IP samples available for nitration. One extra hydroxyl group can be produced for each entangled TEG, HEG or PEG cross-linker unit following the reaction with $\beta C D$ (Figure 1).

The DN generally increased with the degree of cross-linking, but the observed value was higher than the ideal maximum of three per $\beta C D$ unit, indicating the presence of entanglements that increased the number of hydroxyl groups available for nitration in the repeat unit of the cross-linked system (Figure 1).

The oxygen balance $(\Omega)$ of the NT, NH and NP samples was calculated using the following equation: ${ }^{[38]}$

$$
\Omega=-\frac{\left(2 a+\frac{b}{2}-d\right)}{M w} \times 1600 \%
$$

where $a$ is number of carbon atoms, $b$ is the number of hydrogen atoms, $d$ is the number of oxygen atoms, and $M w$ is the molecular weight of the substance.

All the values were negative, ranging from $-66 \%$ (NT) to $-109 \%$ (NP), indicating oxygen-deficient compounds. This reflected their high content of carbon and hydrogen atoms. The values were much lower than those reported for NC $13 \mathrm{~N} \%(-32 \%)^{[39]}$ and $\beta N C D(-40 \%)$. The oxygen balance decreased with the length and quantity of linker units in the cross-linked samples (Figure 11).

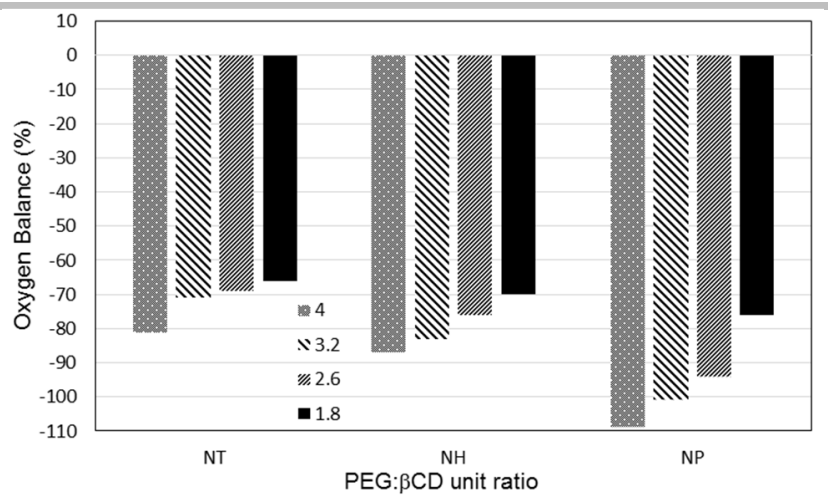

Figure 11 Calculated oxygen balance $(\Omega)$ values of NT, NH and NP samples.

\section{Thermal characterisation}

The decomposition temperature $\left(\mathrm{T}_{\mathrm{dec}}\right)$ and glass transition temperature $\left(T_{g}\right)$ of the inert (IT, IH and IP) and nitrated (NT, NH and NP) samples were determined by differential scanning calorimetry (DSC). ${ }^{[34]}$

The thermal properties of the IT, IH and IP samples were midway between those of their precursors: $\beta C D$ and the TEGDGE, HEGDGE and PEGDGE cross-linkers $(\mathrm{SI})$. The $\mathrm{T}_{\text {dec }}\left(\sim 250{ }^{\circ} \mathrm{C}\right)$ was dependent on the length of the cross-linker (Figure 12), with higher values associated with $\mathrm{IH}$ samples. The decomposition temperatures of IP samples, containing long PEG cross-likers, were much lower than the expected trend, as previously reported. ${ }^{[34]}$ This reflects the polydispersity of the commercial PEGDGE, which also contains various shorter chains, resulting in a lower $\mathrm{T}_{\text {dec }}$ in the blend compared to a pure compound with a similar molecular mass. IT, IH and IP samples produced under the same reaction conditions with the same cross-linker: $\beta C D$ feed ratio showed similar thermal profiles (SI).

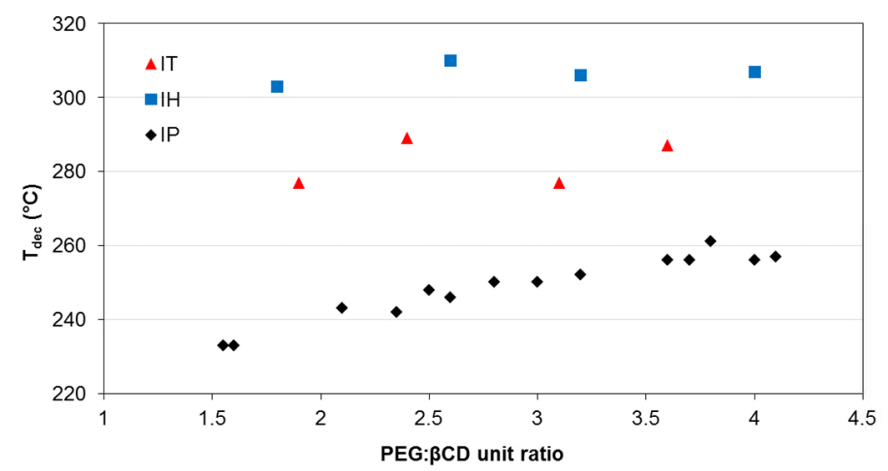

Figure 12 Comparison of decomposition temperatures ( $T_{\text {dec }}$ ) for the IT, IH and IP samples.

The quantity and length of the soft linker chains determined the thermal behaviour of the IT, IH and IP samples at low temperatures. A glass transition was observed in at least part of the products, with a notable shift towards positive $T_{g}$ values compared to the corresponding cross-linkers alone (SI). However, softening was observed in all the tested products even when no glass transition occurred. There was no evidence of a glass transition in the IT samples, suggesting that the length of the TEG units was insufficient to impart mobility to the cross-linked products at low temperatures. However, a general softening was observed in the thermal profile of the IT samples (SI). The 
influence of the length of the soft segments was revealed in the IH samples with HEG: $\beta C D$ unit ratios $>3: 1$ and in IP samples with PEG: $\beta C D$ unit ratios $>2.5: 1$, which were characterised by broad $\mathrm{T}_{\mathrm{g}}$ values with minima of -10 and $-20{ }^{\circ} \mathrm{C}$, respectively (Figure 13).

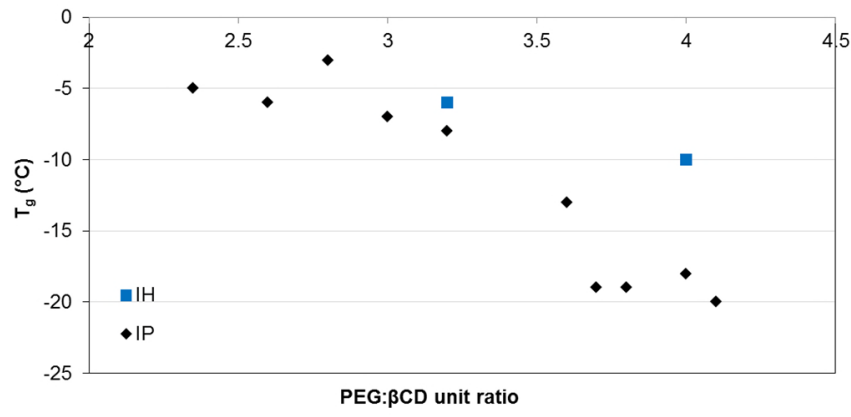

Figure 13 Comparative $\mathrm{T}_{g}$ values of the $\mathrm{IH}$ and IP samples.

The decomposition peaks of the NT, NH and NP samples fell within the range $190-203^{\circ} \mathrm{C}$, comparable to $\mathrm{NC}\left(201-205^{\circ} \mathrm{C}\right)^{[40]}$ and $\beta N C D\left(207^{\circ} \mathrm{C}\right)$. However, the $\Delta \mathrm{H}_{\text {dec }}$ values of the $\mathrm{NT}, \mathrm{NH}$ and NP samples (1360-2080 $\mathrm{J} \mathrm{g}^{-1}$ ) were lower than those observed for NC (1800-2200 $\left.\mathrm{J} \mathrm{g}^{-1}\right)^{[40]}$ and $\beta$ NCD $\left(1990 \mathrm{~J} \mathrm{~g}^{-1}\right)$ due to the lower oxygen content.

The decomposition temperatures of the NT samples remained very close to $200{ }^{\circ} \mathrm{C}$ regardless of the TEG content, whereas the decomposition enthalpies fell within the range 1430-2080 $\mathrm{J} \mathrm{g}^{-1}$ due to their variable nitrogen content. The decomposition temperatures of the $\mathrm{NH}$ samples were $191-199^{\circ} \mathrm{C}$ (Figure 12), whereas the decomposition enthalpies remained constant at 1700 $\mathrm{J} \mathrm{g}^{-1}$. Finally, the decomposition temperatures of the NP samples were $190-197^{\circ} \mathrm{C}$ and the decomposition enthalpies were 1360 $1840 \mathrm{~J} \mathrm{~g}^{-1}$.

As expected, the soft linker segments influenced the thermal properties of NT, NH and NP samples at low temperatures, and the $\mathrm{T}_{\mathrm{g}}$ values were $20-30{ }^{\circ} \mathrm{C}$ higher than the inert precursors. No glass transition was observed in the NT samples (as reported above for the IT analogues), confirming that the length of TEG units was insufficient to keep the derivatives soft and rubbery. In contrast, $\mathrm{T}_{\mathrm{g}}$ values were recorded for all $\mathrm{NH}\left(6\right.$ to $\left.65^{\circ} \mathrm{C}\right)$ and $\mathrm{NP}$ $\left(-14\right.$ to $45^{\circ} \mathrm{C}$ ) samples (Figure 14). These $T_{g}$ values were strongly dependent on the quantity of HEG and PEG units in the samples, with negative values for NP if the PEG: $\beta C D$ unit ratio exceeded 3.2. Generally, the $T_{g}$ values of the nitrated samples were higher than their inert counterparts, probably because the nitrato groups expanded the polar surface area of the compounds, therefore increasing their cohesive energy and limiting chain mobility to an even greater extent than hydrogen bonds. ${ }^{[41]}$

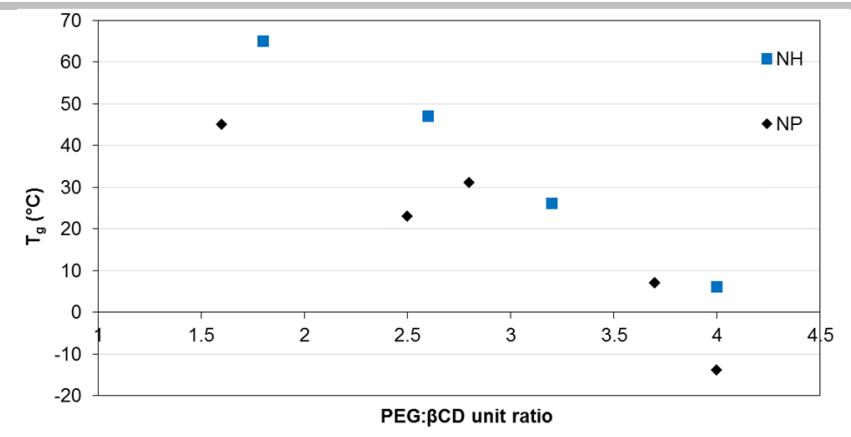

Figure 14 Comparative $\mathrm{T}_{\mathrm{g}}$ values of the NT, NH and NP samples.

\section{Self-healing properties}

The self-healing properties of the IP samples were discussed in our previous study. ${ }^{[34]}$ Here we assessed the self-healing ability of a nitrated polymer sample (NP) with a PEG: $\beta C D$ unit ratio of $4.0: 1$ (Figure 15a). First, the sample was cut (Figure 15b) and then the parts were placed in contact and left to rest for $4 \mathrm{~h}$ at room temperature (Figure 15c). The sample was then gripped at its extremities and pulled gently, revealing a high degree of elongation (Figure 15d).

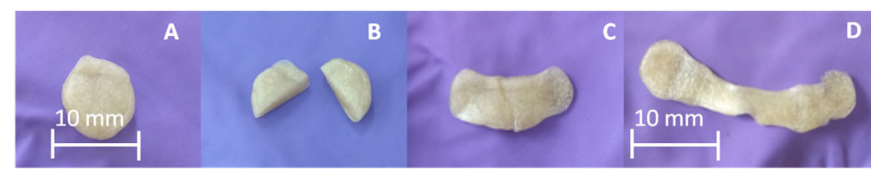

Figure 15 Self-healing ability of NP sample (PEG: $\beta C D$ unit ratio 4.0:1).

The NP sample therefore retained the self-healing ability of its IP precursor. The high concentration of the soft PEG chains facilitated the mobility of the molecule and thus self-healing, even when many of the hydroxyl groups were replaced by nitrato groups. The higher mobility of the dangling PEG chains should also accelerate the self-healing of these compounds (Figure 1).

\section{Hazard tests}

Compatibility tests based on DSC experiments were carried out to determine whether physical contact between the new inert and energetic binders and fillers in an energetic formulation could lead to chemical reactions/interactions and undesirable or unexpected hazards. Representative IT, IH, IP, NT, NH and NP samples were mixed with oxidisers, pyrotechnics and high explosives, and preliminary DSC compatibility tests were carried out according to STANAG 4147 (edition 2) Test $4 .^{[31]}$ Inert polymeric IT, IH and IP samples were compatible with potassium nitrate, potassium chlorate and pentaerythritol tetranitrate (PETN) but the decomposition profiles showed minor changes when mixed with the explosive HMX suggesting that some HMX molecules become enclosed in the $\beta C D$ cavity, reflecting the enveloping properties of $\beta C D$ and the design of the new binder. The decomposition curves of binders with the explosive RDX, ammonium dinitramide (ADN), ammonium nitrate and red phosphorus were broader, with $T_{\text {dec }}$ values for the energetics shifted by $4-23{ }^{\circ} \mathrm{C}(\mathrm{SI})$. The compatibility of an NP sample (PEG: $\beta C D$ unit ratio 3.8:1) with the energetics listed above has already been published, and similar results were reported. ${ }^{[10]}$

Small-scale hazard tests developed at the Centre for Defence Chemistry at Shrivenham were performed on representative 
samples of NT, NH and NP. The aim of the tests was to determine the external stimuli that would cause the energetic binders to ignite compared with those reported for $\beta N C D .{ }^{[10]}$ The tests were not standardised methods to characterise the energetic properties of a material precisely and the results indicate a degree of "hazardous" (GO/no-GO) and cannot be expressed in $\mathrm{J}$ or $\mathrm{N}$. They were carried out to provide a degree of confidence in handling the new materials prior to Energetic Materials Testing and Assessment Policy (EMTAP) tests on a larger scale. They comprised (i) an impact and friction sensitivity test; (ii) colour change tests to assess thermal stability; and (iii) temperature ignition tests to assess combustion properties.

None of the samples changed colour after $24 \mathrm{~h}$ at room temperature, but they turned brown when incubated at $100{ }^{\circ} \mathrm{C}$ for $30 \mathrm{~min}$ reflecting the decomposition of nitroesters. We found that $\beta N C D$ was sensitive to impact in the steel-on-steel impact test, with a GO score of $7 / 10$ based on counting positive (GO) and negative (no-GO) events (Table 1). The NP samples were insensitive to the test stimuli regardless of the PEG: $\beta C D$ unit ratio (Table 1), with $0 / 10 \mathrm{GO}$ in the mallet and anvil impact and friction tests. Unlike the rigid structure of $\beta N C D$, the soft PEG chains in the NP samples dissipated the kinetic energy of the stimulus and facilitated impact absorption. $\mathrm{NH}$ samples were susceptible to impact when the HEG: $\beta C D$ unit ratio was $\leq 2.6: 1$, whereas NT samples were not significantly sensitive to impact with GO scores of $1 / 10$ or $2 / 10$, and can therefore be considered 'moderately hazardous'. The shorter length of the soft TEG chains did not completely desensitise the NT samples in contrast to the samples of $\mathrm{NH}$ and $\mathrm{NP}$.

Further hazard tests followed the certification methods presented in the EMTAP Manual of Tests. ${ }^{[32]}$ Each test is based on the repetition of several forms of analysis to increase confidence in the result. The Rotter impact test (Test $1 \mathrm{~A})$ and ESD test (Test 4) were performed on one large NP sample $(10 \mathrm{~g})$ obtained by dissolving and blending in acetone the products of four nitration reactions at the $2.5 \mathrm{~g}$ scale using the IP precursor with a PEG: $\beta C D$ unit ratio of $3.8: 1$.

Table 1 Small-scale hazard tests performed on NT, NH and NP samples according the small-scale hazard tests protocol developed at the Centre for Defence Chemistry at Shrivenham.

\begin{tabular}{|c|c|c|c|}
\hline Sample & Linker: $\beta C D$ unit ratio ${ }^{1}$ & $\begin{array}{l}\text { Impact } \\
(\mathrm{GO})^{2}\end{array}$ & Friction \\
\hline$\beta N C D$ & - & $7 / 10$ & $0 / 10$ \\
\hline \multirow{5}{*}{ NP } & 4.0 & $0 / 10$ & $0 / 10$ \\
\hline & 3.7 & $0 / 10$ & $0 / 10$ \\
\hline & 2.8 & $0 / 10$ & $0 / 10$ \\
\hline & 2.5 & $0 / 10$ & $0 / 10$ \\
\hline & 1.6 & $0 / 10$ & $0 / 10$ \\
\hline \multirow{4}{*}{$\mathrm{NH}$} & 4 & $0 / 10$ & $0 / 10$ \\
\hline & 3.2 & $0 / 10$ & $0 / 10$ \\
\hline & 2.6 & $1 / 10$ & $0 / 10$ \\
\hline & 1.8 & $2 / 10$ & $0 / 10$ \\
\hline \multirow{4}{*}{ NT } & 3.6 & $1 / 10$ & $0 / 10$ \\
\hline & 3.2 & $1 / 10$ & $0 / 10$ \\
\hline & 2.5 & $1 / 10$ & $0 / 10$ \\
\hline & 1.6 & $2 / 10$ & $0 / 10$ \\
\hline
\end{tabular}

1 Based on ${ }^{1} \mathrm{H}$ NMR data.

$2 \mathrm{GO}$ is the indication of ignition assessed by the development of sound and smoke.

The Rotter impact test for the blend indicated a dimensionless figure of insensitiveness (Fol) of 30 . This is compared to a Fol of 80 for a standardized RDX specimen, tested on the same machine. $30 \mathrm{mg}$ samples were impacted, and when initiated released on average $1 \mathrm{~cm}^{3}$ of gas. The initiated samples were not completely consumed, indicating a localised initiation as seen in the small-scale tests described above. The Fol value indicated that the compound was 'very sensitive' to impact, given that sensitive compounds have values in the range $100 \geq \mathrm{Fol} \geq 30$, and initiators have Fol values $<30$. The impact sensitiveness of the NP sample was comparable to that of a NC gun propellant formulation ( $\mathrm{Fol}=20-30)$.

The ESD test, reporting the mean effect of 50 discharges, determines the sensitiveness of a sample to electrostatic initiation. The NP sample (PEG: $\beta C D$ ratio 3.8:1) did not ignite at $4.5 \mathrm{~J}$, whereas $\beta N C D$ ignites at $0.0125 \mathrm{~J}^{[11]}$ and nitrated $\beta C D$ crosslinked with epichlorohydrin ignites at $0.1288 \mathrm{~J}^{[12]}$

\section{Stability of NT, NH and NP samples}

The thermal stability of NT, NH and NP samples was tested at $80^{\circ} \mathrm{C}$ by heat flow calorimetry (HFC) according STANAG 4582. ${ }^{[42]}$ Four lots $(\sim 1 \mathrm{~g})$ of an NP sample (PEG: $\beta C D$ unit ratio $4: 1)$ were prepared, one of which was retained as a control whereas the others were mixed with one of three stabilisers: diphenylamine (DPA), 2,4-dinitrophenylamine (2,4-NDPA) or ethyl centralite (EC). These are commonly used with $\mathrm{NC}$ as a $1 \% \mathrm{w} / \mathrm{w}$ formulation, and the same proportion was used in our experiments. A sample of pure (non-stabilised) $12.6 \mathrm{~N} \% \mathrm{NC}$ was also tested for comparison.

The heat flow from the samples was measured at a constant temperature of $80^{\circ} \mathrm{C}$ for 10.6 days as specified by STANAG 4582 . The method states that the sample should have a heat flow of < $114 \mu \mathrm{W} \mathrm{g}$ g $^{-1}$ after $254 \mathrm{~h}$ (Figure 16, dotted line) in order to be defined as stable for up to 10 years equivalent storage at $25^{\circ} \mathrm{C}$.

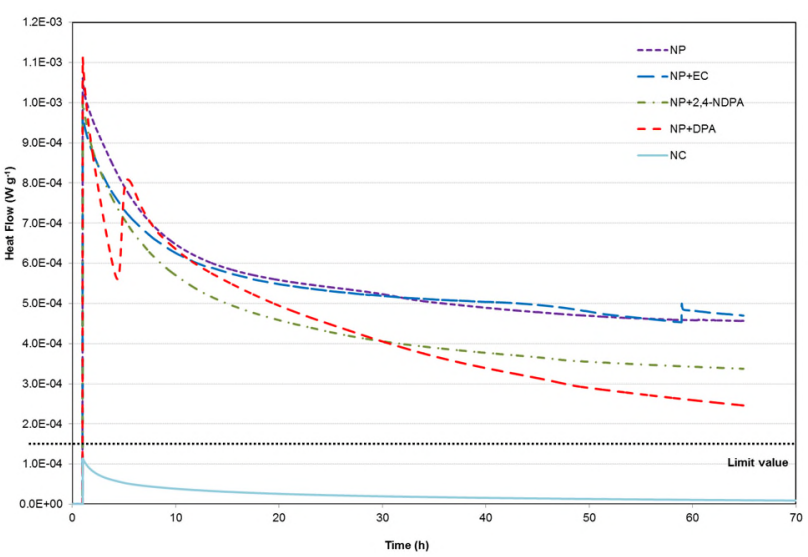

Figure 16 Thermal stability of the NP sample alone (dotted line) and in the presence of $1 \%(w / w)$ of the stabilisers ethyl centralite (long dashed line), 2,4NDPA (dashed-dotted line) and DPA (dashed line). The grey solid line below the limit value shows the thermal stability of pure NC. 
The experiment was terminated after $70 \mathrm{~h}$ due to the high heat flow values that were recorded. All NP samples containing the energetic binder were unstable during the test (Figure 16). The heat flow for NC was lower than the limit value of $114 \mu \mathrm{W} \mathrm{g}^{-1}$ (solid curve). The viscous consistency of the sample at $80^{\circ} \mathrm{C}$ is thought to influence its stability because liquid materials decompose more quickly than crystalline solids. ${ }^{[43,44]}$ The air and moisture trapped in the spongy matrix of the samples, as well as that in the head space of the vials, probably accelerated the decomposition, as reported for other nitroesters. ${ }^{[45]}$ The addition of ethyl centralite did not change the stability compared to pure NP, but the addition of DPA or 2,4-NDPA reduced the heat flow, indicating they are suitable as chemical stabilisers.

Future work will determine the quantity of stabilisers remaining throughout the experiment. ${ }^{[42,43,45]}$ The samples were analysed before and after testing by ${ }^{1} \mathrm{H}-\mathrm{NMR}$ spectroscopy, which showed that the stabilisers decomposed during the experiment, confirming the reaction with the degradation products $\left(\mathrm{NO}_{\mathrm{x}}\right)$ from the energetic binder (SI). The aged samples were also thermally characterised by DSC. The $T_{\text {dec }}$ was not significantly affected by exposure to a constant temperature of $80{ }^{\circ} \mathrm{C}$ for $70 \mathrm{~h}(\mathrm{SI})$. The presence of stabilisers slightly improved the stability of NP, increasing the $T_{\text {dec }}$ marginally $\left(<3{ }^{\circ} \mathrm{C}\right)$ compared to the pure sample, but the variations were small and within the error range of the analytical method.

\section{Conclusions}

We synthesised a set of novel inert and nitrated binders from $\beta C D$ s and diglycidyl ether cross-linkers (TEGDGE, HEGDGE and PEGDGE), which exhibited physical, chemical and thermal properties dependent on the length and quantity of the soft segments (TEG, HEG and PEG). The chemical structures of all samples were determined by ${ }^{1} \mathrm{H}-\mathrm{NMR}$ and FTIR spectroscopy and the polymeric nature of the products was also confirmed by SEM and GPC. The inert binders were soluble in water, whereas their nitrated analogous were dissolved in organic solvents, confirming their processability as binders.

The softness of the inert samples was directly dependent on the length of the linker unit and the cross-linking ratio. A glass transition at temperatures higher than $-20^{\circ} \mathrm{C}$ was detected in the inert and nitrated samples if the HEG or PEG segments exceeded a molar ratio of $3.7: 1$ with respect to the rigid $\beta C D$ units. The inert and nitrated derivatives containing PEG units showed self-healing ability at temperatures $\geq 25{ }^{\circ} \mathrm{C}$, indicating hydrogen bonding between the molecules.

The decomposition temperatures of the inert compounds were linearly dependent on the length of the soft segment $\left(232-310^{\circ} \mathrm{C}\right)$ whereas all the nitrated derivatives degraded at $\sim 200{ }^{\circ} \mathrm{C}$ with variable associated degradation energies (1400-2100 $\left.\mathrm{J} \mathrm{g}^{-1}\right)$ depending on the degree of cross-linking and the nitrogen content. Hazard tests confirmed that the soft segments reduced the impact sensitiveness of the nitrated binders compared to the $\beta N C D$ sample, and nitrated cross-linked $\beta C D$ s containing the longer linker segment (PEG) were insensitive to an ESD of $4.5 \mathrm{~J}$ and the Fol was 30 . HFC showed the nitrated binders were significantly less stable than $\mathrm{NC}$ at $80^{\circ} \mathrm{C}$. The presence of stabilisers often used with NC slightly improved their stability.

Nitrated binders have been shown to have comparable hazard properties to NC and NC-based propellants. Further work is required to improve their chemical stability and find effective chemical stabilisers. However, the new inert and nitrated binders offer promising solutions as components for energetic formulations due to their low glass transition temperatures, processability, and low sensitiveness to impact and ESD.

\section{Experimental Section}

\section{Materials}

We used $\beta C D$ (97\%, Sigma-Aldrich) with a water content of 11$13 \%$, based on TGA data. PEGDGE $500 \mathrm{Mw}$ (Sigma-Aldrich), $\mathrm{NaOH}$ (Fisher Chemicals), benzylated dialysis membranes with a molecular weight cut-off (MWCO) of 2000 (Sigma-Aldrich), epichlorohydrin (Sigma-Aldrich), tetrabutyl ammonium bromide (Sigma-Aldrich), HEG (Sigma-Aldrich) and TEG (Sigma-Aldrich) were used without further purification. TEGDGE $\left(262 \mathrm{~g} \mathrm{~mol}^{-1}\right)$ and HEGDGE (394 $\mathrm{g} \mathrm{mol}^{-1}$ ) were synthesised in house. ${ }^{[33]}$ The $\mathrm{IP} / \mathrm{IT} / \mathrm{IH}$ and NP/NT/NH samples were prepared as previously described. ${ }^{[33]}$

\section{Instrumentation and analytical methods}

The ${ }^{1} \mathrm{H}-\mathrm{NMR}$ spectra were recorded on a Bruker Ascend $400 \mathrm{MHz}$ spectrometer in DMSO- $d_{6}$ and $D_{2} \mathrm{O}$. Signals representing the solvents served as internal standards. The solvent peaks were referenced to $2.5 \mathrm{ppm}\left(\mathrm{DMSO}-\mathrm{d}_{6}\right)$ and $4.7 \mathrm{ppm}\left(\mathrm{HDO}, \mathrm{D}_{2} \mathrm{O}\right)$. Peak multiplicities were described as follows: singlet (s), multiplet $(\mathrm{m})$, and broad (br). FTIR spectra were collected using a Bruker Alpha spectrometer in ATR mode. A Waters size-exclusion chromatography system equipped with a 2410 refractive index detector set at $35^{\circ} \mathrm{C}$ was used to determine the molar mass averages and molar mass distribution of the polymers. The samples were dissolved in distilled water or THF to achieve concentrations of 1.0 and $1.5 \mathrm{mg} \mathrm{ml}^{-1}$ respectively. The injection volume was $100 \mu \mathrm{l}$ and a $1 \mathrm{ml} \mathrm{min}^{-1}$ flow rate was maintained through two columns in series held at $35{ }^{\circ} \mathrm{C}$. For the samples dissolved in water, Agilent Technologies PL aquagel-OH MIXEDM columns (1000-500,000 Da, $8 \mu \mathrm{m}, 300 \times 7.5 \mathrm{~mm}$ ) were used with a mobile phase comprising $0.5 \%(\mathrm{w} / \mathrm{w}) \mathrm{NaN}_{3}$ in $0.01 \mathrm{M} \mathrm{LiNO}_{3}$. For the nitrated samples dissolved in THF, Agilent Technologies PLgel $10 \mu \mathrm{m}$ mixed-phase B columns $(8 \mu \mathrm{m}, 300 \times 7.5 \mathrm{~mm})$ were used with a mobile phase of THF stabilised with butylated hydroxytoluene. The aquagel columns were calibrated using Agilent Technologies EasyVial PEO/PEG standards (400 Da to $1.4 \mathrm{MDa}$ ) in $10 \mathrm{ml}$ buffer, whereas the PLgel columns were calibrated using Agilent Technologies EasiCal PS1 (580-7.5 $\mathrm{MDa}$ ) in $10 \mathrm{ml}$ THF. Each sample was injected as five replicates and the averaged data were reported as PEO/PEG equivalent molar masses for the water-soluble polymers or polystyrene equivalent molar masses for the THF-soluble polymers. The data were acquired and processed using Waters Empower 2 software. Thermal analysis of the samples (1.0-15.0 mg) was carried out using Mettler Toledo DSC3+, TGA/DSC3+ and DSC30 devices at the heating rate of $10^{\circ} \mathrm{C} \mathrm{min}-1$ under an inert $\mathrm{N}_{2}$ atmosphere. The temperature was cycled three times to eliminate the water present in the samples and all experiments were carried out in triplicate. SEM was conducted using a Hitachi SU 3500 instrument which is a tungsten filament variable pressure device with an accelerating voltage of $20 \mathrm{kV}$ at $80 \mathrm{~Pa}$. Samples $(5 \mathrm{mg})$ were pressed onto conductive carbon tabs and supported with specimen stubs. The stability of one nitrated product was determined by HFC. The samples $(1.0 \mathrm{~g})$ were placed in $3-\mathrm{ml}$ disposable glass ampules with glass beads to fill the head space. The samples were 
characterised by isothermal calorimetry at $80^{\circ} \mathrm{C}$ in a TAM IV minicalorimeter $(4 \mathrm{ml}, 6.9 \mathrm{~J} / \mathrm{K})$ with a dedicated software package.

\section{Compatibility tests}

The compatibility tests were based on STANAG 4147 Test 4 . We analysed $0.5-1.0 \mathrm{mg}$ of each material by DSC at a heating rate of $2{ }^{\circ} \mathrm{C} \mathrm{min}{ }^{-1}$ under $\mathrm{N}_{2}$ and then a mixture of the two materials was measured in the same manner. Any alteration in the shape, onset, or peak position of any measured thermal event was considered indicative of incompatibility. Under "Applicability", STANAG 4147 Test 4 states: "This test is applicable to explosives likely to come into contact with plasticizers, fuels, additives, polymeric materials and other explosives." It also states: "This test is not concerned with compatibility between ingredients in explosive compositions and the consequent stability of such compositions." Even so, the method allows a large number of mixtures to be investigated rapidly. As such, the results from the tests are useful but not conclusive, and further experiments are required, such as vacuum stability testing. Any shifts in thermal events that vary by less than $4{ }^{\circ} \mathrm{C}$ indicate compatibility, whereas shifts of $4-20{ }^{\circ} \mathrm{C}$ are inconclusive and shifts greater than $20^{\circ} \mathrm{C}$ are considered conclusive evidence that materials are incompatible.

\section{Hazard testing}

The direct impact, glancing blow, high temperature, room temperature and flame tests (30 $\mathrm{mg}$ of compound) were not standardised methods to characterise the energetic properties of a material precisely, developed at the Centre for Defence Chemistry at Shrivenham. They designed to risk assess the new materials and provide a degree of confidence in handling prior to Energetic Materials Testing and Assessment Policy (EMTAP) tests on a larger scale.

Direct impact: steel hammer on steel anvil. A small amount of the synthesised compound ( $30 \mathrm{mg}$ ) was placed on the steel anvil and struck with the steel hammer. The test was carried out 10 times. Signs of decomposition, such as smell, colour change and material consumption, were evaluated after each blow.

Glancing blow: steel hammer on steel anvil. A small amount of the synthesised compound ( $30 \mathrm{mg}$ ) was placed on the steel anvil and struck with a glancing blow using the curved edge of the steel hammer. The test was carried out 10 times. Signs of decomposition were evaluated after each blow as above.

High temperature test. A small amount of compound (30 mg) was placed on a steel plate at $100{ }^{\circ} \mathrm{C}$ for $30 \mathrm{~min}$. Signs of decomposition were evaluated as above.

Room temperature test. A small amount of compound (30 mg) was placed on a steel plate at $30{ }^{\circ} \mathrm{C}$ for $24 \mathrm{~h}$. Signs of decomposition were evaluated as above.

Flame test. A small amount of compound ( $30 \mathrm{mg}$ ) was placed on a steel spoon and ignited using a blow torch. The nature of the combustion process was described by an expert member of the Cranfield University "Synthesis and Formulation" group.

ESD and Rotter impact hazard tests followed the certification methods presented in the EMTAP Manual of Tests. ${ }^{[32]}$

EMTAP No. 6 (ESD) test. This test was the Electric Spark Test no. 6 as described in the EMTAP Manual of Tests, issue 5,
November 2016. Test samples are subjected to discharges of 4.5 , 0.45 and $0.045 \mathrm{~J}$. Nylon spark test strips were filled with the material and sealed with copper tape. Up to 50 tests were performed at each of the three energy levels to determine a minimum spark energy that causes ignition. The samples were inspected for perforation or signs of decomposition.

EMTAP No. 1 (Rotter impact) test. This test was the Rotter impact test $1 \mathrm{~A}$ as described in the EMTAP Manual of Tests, issue 5, November 2016. The Bruceton staircase procedure was used to establish median drop heights for the test material and this was used to determine the Fol value. Samples $(30-40 \mathrm{mg}$ ) were placed in a concavity at the centre of the supporting frame of the Rotter test apparatus. A free-fall weight $(5 \mathrm{~kg})$ and striker were suspended above. The tests followed the Bruceton "up and down" testing technique with 50 replicates and the results were based on the height at which the compound was initiated $50 \%$ of the time, with the mean height reported as the Fol. The Fol results were presented relative to $\mathrm{RDX}$, where Fol $>80$ indicates a material that is less sensitive than RDX, and Fol $<80$ indicates a material that is more sensitive than RDX to impact initiation. Initiation was determined by the observation of parameters such as sound, smoke, flash and volume of gas released immediately after impact, and is therefore affected by operator judgment.

\section{Acknowledgements}

This project was funded by the Defence Science and Technology Laboratory (Dstl) via the Weapons Science and Technology Centre (WSTC). The authors would like to thank Dr Jonathan Painter for the assistance with SEM experiments, Roxel UK for kindly providing the ADN sample, and BAES Land for assistance in the exploitation of this work.

Keywords: $\beta$-cyclodextrin • cross-linking • polyethylene glycol • inert binder $\bullet$ nitrated binder

\section{References}

[1] R. L. Beauregard, "The History of Insensitive Munitions," http://www.insensitivemunitions.org/history/preface/

[2] H. G. Ang, S. Pisharath, G. G. Ang; Pisharath Sreekumar, H. G. Ang, S. Pisharath, Energetic Polymers - Binders and Plasticizers for Enhancing Performance., Wiley-VCH, 2012. ISBN: 978-3-52733155-0

[3] R. G. Stacer, D. M. Husband, Propellants, Explos. Pyrotech. 1991, 16,167-176. DOI: 10.1002/prep.19910160404

M. E. Colclough, H. Desai, R. W. Millar, N. C. Paul, M. J. Stewart, P. Golding, Polym. Adv. Technol. 1994, 5, 554-560. DOI: 10.1002/pat.1994.220050914

[5] T. M. Junisbekov, V. N. Kestelman, N. I. Malinin, Stress Relaxation in Viscoelastic Materials, Science Publishers, 2003. ISBN: 1578082587

[6] E. Dossi, J. Akhavan, S. E. Gaulter, R. G. Williams, W. J. Doe, Propellants, Explos. Pyrotech. 2018, 43, 241-250. DOI:10.1002/prep.201700220

[7] Arthur Provatas, DSTO-TR-0966, DSTO, 2000, http://www.pyrobin.com/files/Energetic\%20Polymers3.pdf 
[8] P. Golding, A. J. Bellamy, A. E. Contini, E. Dossi, Polyphosphazenes, WO 2013190260 A2 20131227, 2013.

[9] H. Abusaidi, M. Ghorbani, H. R. Ghaieni, Propellants, Explos. Pyrotech. 2017, 42, 671-675. DOI: 10.1002/prep.201600120

[10] F. Luppi, H. Cavaye, E. Dossi, Propellants, Explos. Pyrotech. 2018, 43,1-10. DOI: 10.1002/prep.201800137

[11] J. P. Consaga, S. L. Collignon, Pat. US/1992/5114506. Int. Appl. CO6B 25/00 1992.

[12] A. Ruebner, G. L. Statton, J. P. Consaga, WO 03/081164, 2003.

[13] J. Szejtli, Chem. Rev. 1998, 98, 1743-1754. DOI: $10.1021 / \mathrm{cr} 970022 \mathrm{c}$

[14] A. R. Khan, P. Forgo, K. J. Stine, V. T. D'Souza, Chem. Rev. 1998, 98, 1977-1996. DOI: 10.1021/cr970012b

[15] G. Gattuso, C. Gargiulli, M. F. Parisi, Int. J. Mol. Sci. 2007, 8, 10521063. DOI: $10.1021 / \mathrm{cr} 960133 w$

[16] N. T. Tavengwa, N. Hintsho, S. Durbach, I. Weiersbye, E. Cukrowska, L. Chimuka, J. Environ. Chem. Eng. 2016, 4, 24502457. DOI: 10.1016/j.jece.2016.04.024

[17] T. W. Sheremata, J. Hawari, Environ. Sci. Technol. 2000, 34, 34623468. DOI: 10.1021/es9910659

[18] S. Cahill, F. J. Owens, J. Phys. Chem. 1994, 98, 7095-7100. DOI: 10.1021/j100079a033

[19] P. Maksimowski, T. Rumianowski, Cent. Eur. J. Energ. Mater. 2016, 13, 217-229. DOI: 10.22211/cejem/64973

[20] H. Kono, T. Nakamura, H. Hashimoto, Y. Shimizu, Carbohydr. Polym. 2015, 128, 11-23. DOI: 10.1016/j.carbpol.2015.04.009

[21] O. Radia, E. Rogalska, G. Moulay-Hassane, Pharm. Dev. Technol. 2012, 17, 632-637. DOI: 10.3109/10837450.2011.565347

[22] D. Zhao, L. Zhao, C. Zhu, Z. Tian, X. Shen, Carbohydr. Polym. 2009, 78, 125-130. DOI: 10.1016/j.carbpol.2009.04.022

[23] F. Van De Manakker, T. Vermonden, N. El Morabit, C. F. Van Nostrum, W. E. Hennink, Langmuir 2008, 24, 12559-12567.

DOI: 10.1021/la8023748

[24] S. Salmaso, A. Semenzato, S. Bersani, P. Matricardi, F. Rossi, P. Caliceti, Int. J. Pharm. 2007, 345, 42-50. DOI: 10.1016/j.jpharm.2007.05.035

[25] T. T. Nielsen, V. Wintgens, K. L. Larsen, C. Amiel, J. Incl. Phenom. Macrocycl. Chem. 2009, 65, 341-348.

DOI: $10.1007 / s 10847-009-9591-0$

[26] L. C. Cesteros, C. A. Ramírez, A. Peciña, I. Katime, J. Appl. Polym. Sci. 2006, 102, 1162-1166. DOI: 10.1002/app.24390

[27] A. Klaewklod, V. Tantishaiyakul, N. Hirun, T. Sangfai, L. Li, Mater. Sci. Eng. C 2015, 50, 242-250. DOI: 10.1016/j.msec.2015.02.018

[28] T. Miao, S. L. Fenn, P. N. Charron, R. A. Oldinski, Biomacromolecules 2015, 16, 3740-3750. DOI: 10.1021/acs.biomac. 5 b00940

[29] A. J. Poudel, F. He, L. Huang, L. Xiao, G. Yang, Carbohydr. Polym. 2018, 194, 69-79. DOI: 10.1016/j.carbpol.2018.04.035
[30] A. Myburgh, J. Therm. Anal. Calorim. 2006, 85, 135-139. DOI: $10.1007 /$ s10973-005-7357-5

[31] STANAG 4147 (Ed. 2), "Chemical Compatibility of Ammunition Components with Explosives (Non-Nuclear Applications)," 2001.

[32] Energetic Materials Testing Assessment Policy Manual of Tests (EMTAP) Manual of Tests, 2007.

[33] M. Glor, J. Electrostat. 1985, 16, 175-191. DOI: 10.1016/03043886(85)90041-5

[34] F. Luppi, G. Kister, M. Carpenter, E. Dossi, Polym. Test. 2019, 73, DOI 10.1016/j.polymertesting.2018.11.034.

[35] J. P. Consaga, L. Plata, US 006293201B1, 2001.

[36] Y. Maréchal, Yves, J. Mol. Struct. 2011, 1004, 146-155. DOI: 10.1016/j.molstruc.2011.07.054

[37] I. M. Kolthoff, E. B. Sandell, B. Moskovitz, J. Am. Chem. Soc. 1933, 55, 1454-1457. DOI: 10.1021/ja01331a020

[38] J. Akhavan, The Chemistry of Explosives, Royal Society Of Chemistry, London, 2004, Chapter. 5, 2, ISBN: 978-0-85404-640-9

[39] U. Teipel, Energetic Materials: Particle Processing and Characterization, Wiley-VCH, 2005, Chapter 1, 2, ISBN: 978-3-52730240-6

[40] S. M. Pourmortazavi, S. G. Hosseini, M. Rahimi-Nasrabadi, S. S. Hajimirsadeghi, H. Momenian, J. Hazard. Mater. 2009, 162, 11411144. DOI: 10.1016/j.jhazmat.2008.05.161

[41] S. J. Park, M. K. Seo, Interface Sci. Technol. 2011, 18, 147-252. DOI: 10.1016/B978-0-12-375049-5.00003-7

[42] B. Vogelsanger, Chim. Int. J. Chem. 2004, 58, 401-408. DOI: $10.2533 / 000942904777677740$

[43] G. B. Manelis, Thermal Decomposition and Combustion of Explosives and Propellants, Taylor \& Francis, 2003. ISBN: 9780415299848

[44] Y. M. Burov, "Thermal Decomposition of Solid Energetic Materials," http://www.abitura.com/modern physics/x1.html [45] D. Trache, A. F. Tarchoun, J. Mater. Sci. 2018, 53, 100-123. DOI: 10.1007/s10853-017-1474-y 


\section{FULL PAPER}

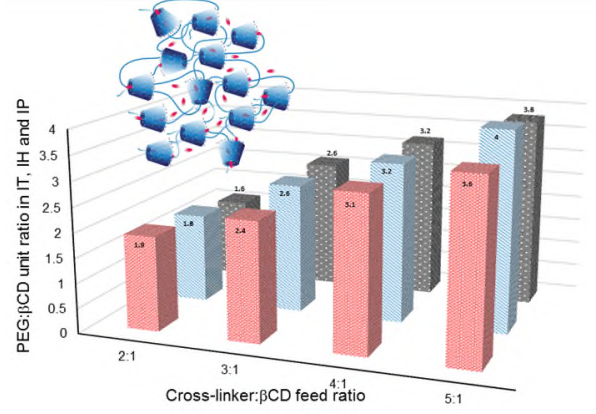

Federico Luppi, Nathalie Mai, Guillaume Kister, Philip P. Gill, Sally

E. Gaulter, Christopher Stennet, and Eleftheria Dossi*

1-9

Chemical modification of $\beta$-cyclodextrins: Balancing soft and rigid domains in complex structures

[a] Dr Federico Luppi, Dr Nathalie Mai, Dr Guillaume Kister, Dr Philip P. Gill, Miss Sally E. Gaulter, Dr Christopher Stennet, Dr Eleftheria

Centre for Defence Chemistry, Cranfield University 